\title{
Electrotechnical complex of drill rig with adjustable electric drives
}

\author{
Oleg Nikulin ${ }^{1, *}$ and Vitaliy Shabanov ${ }^{2}$ \\ ${ }^{1}$ Management Company Tatburneft, LLC Almetievsk, 51 Fahretdin Street, 423450, Russia \\ ${ }^{2}$ Ufa State Petroleum Technological University (USPTU), Electrotechnical and Electrical Equipment of Enterprises, 1 Kosmonavtov \\ Street, 450044, Russia
}

\begin{abstract}
The paper considers the electrotechnical complex of a drill rig with adjustable electric drives of the main mechanisms. A computer model has been developed for the electrical complex of the drill rig, which allows studying processes in case of interruptions in the power supply system, changes in the technological parameters of drilling, etc. The article presents the simulation results for short circuits in the power supply system of the drilling rig and for drilling a well.
\end{abstract}

\section{Introduction}

Drill rig power supply is implemented by electric networks from 6 to $10 \mathrm{kV}$. In most cases drill rig power supply is implemented mainly from weak electric networks of commensurate capacity or autonomous power supply systems [1]. At the same time, the requirements to control systems of drill rig are increasing $[2,3]$, the operating conditions of electric drives and relay protection become more complicated and increase the relevance of developing computer models of electrotechnical complex of drill rig (ETC DR).

Computer models of ETC DR use the experience of developing models of relay protection systems [4], electric motors [5, 6] and power supply systems [7]. Modelling of ETC DR is widely used for research and analysis of the mutual influence of the electric power source and the main electric drives of the drilling rig, both in production drilling and in the construction of geological exploration wells due feeding the drilling rig from autonomous diesel power plants, including for studying the quality of electricity in various modes work of the main electric drives. Such studies, implemented in [8], allow establishing that the use of a frequencycontrolled asynchronous electric motor makes it possible to improve the electromagnetic compatibility of the electric power source and the main drive of the drilling rig while they work together and reduce the cost of energy supply. Electric drive of drill winches works in a short-time mode with frequent starts. This determines the important role of research and optimization of launching modes. Studies of the ETC DR in the start-up modes with the use of mathematical modelling in the MATLAB/Simulink software allow obtaining the dependence of the characteristics of an uncontrolled and frequency-controlled asynchronous electric motor upon its starting from time and on the parameters of the power supply network [8]. Comparison of the obtained dependences has shown that the use of a frequencycontrolled asynchronous electric drive allows reducing the average starting current of the electric motor by $80 \%$ and reducing the voltage deviation in the electric network by $60 \%$. Comparison of the maximum values of active and full powers during the start-up of an uncontrolled and frequency-controlled asynchronous electric motor has shown that the use of a frequency converter allows choosing a diesel generator by power 1.5 times less than in the case of an unregulated electric drive. This makes it possible to more fully use the diesel engine in terms of power and, thereby, reduce the consumption of energy resources during the construction of the well.

In work [9], using mathematical modelling in the MATLAB/Simulink software, the authors studied the effect of defects and malfunctions of asynchronous drilling rig engines on the electric network. On the basis of results of the research, oscillograms of the change in the active and reactive power of the induction motor consumed from the network were obtained in the presence of rotor malfunctions and a significant effect of the faulty motor on the power quality indicators and the power consumed by the drilling rig was revealed. It is shown that the presence of rotor defects in the motor leads to modulation of the amplitude of the supply voltage, which leads to significant variations in the speed of the electric motors of the drilling mechanisms and increases the active, reactive and full power consumed by them. All these factors reduce the mechanical drilling speed, increasing the time, energy and economic costs of the well construction.

Electrotechnical complex of DR as a research object is inextricably linked with the technological process of drilling, the kinematics of drilling mechanisms and their loads, which should also be taken into account in modelling. It is important to take into account the

* Corresponding author: oleg309@yandex.ru 
properties of the drill string while modelling the electromechanical transient processes in the ETC DR. So in [10] the structural model of the drill string is considered, as a consecutive connection of elementary links. A study of this structure on dynamic properties was performed using a package of mathematical programs MatLab. The analysis of transient processes for various operating modes of the drill string is implemented. In [11], studies of electromechanical processes in the ETC DR were implemented taking into account the properties of the drill string for the DR with an autonomous power supply from the diesel power station during geological prospecting drilling.

This review shows the relevance of the development of computer models of ETC DR taking into account the power supply system and the actual technological parameters of the drilling process. Consider the development of the computer model ETC DR on the example of drilling rig BU-2000 / 125EP, a single-line power supply scheme which is shown in Figure 1.

Computer models of the electrotechnical complex of drill rig use experience modelling systems relay protection [4], electric motors [5, 6] and electricity [7]. The paper considers the development of a computer model. This development is based on the example of electrotechnical complexes of drill rig, the drill rig's power supply single-line diagram, which is shown in Figure 1.

\section{Methods used for experiments}

To create and research the electrotechnical complex of drill rig we will use the MATLAB system. This system is based on algorithms of vector computation, providing high speed and accuracy of calculations, as well as the possibility of visual control of the processes occurring in the model. Merging the SIMULINK package and the vast library of electrical units of the package SimPowerSystem in the system MATLAB provides the ability to construct simulation and functional models of complex electrical systems, including the electrotechnical complexes of drill rig [8].

The model contains the following blocks and subsystems (Fig.2): source voltage -Three-PhaseSource, voltage $6000 \mathrm{~V}$, frequency $50 \mathrm{~Hz}$; «Airline-PowerLine» is represented by a block of Three-PhaseSeries RLC Branchjob. In the task window is introduced the system settings of the external power supply; three-phase AC switches HVVS1...HVVS4. Control of the switches is effected by signaling to the com port. A single level of the control signal causes the closure of the keys, and the zero level is the command to open the keys. In addition, the disconnection of the circuit in each phase is performed when the current reaches this zero level [8].

To measure amperage and voltage meters M1 ... M4 were used; three-phase transformers - T_TD $(6 \mathrm{kV} / 600 \mathrm{~V}$, $1100 \mathrm{kVA}$ for power supply of the top drive system (TD)), T_DW (6kV/400V $1000 \mathrm{kVA}$ for electric power draw-works (DW)) and T_MP $(6 \mathrm{kV} / 400 \mathrm{~V}, 1600 \mathrm{kVA}$ power for electric drive drill pump (MP)); rectifier R_TD and invertor I_TD of the upper drive system; DC rectifiers of electric motors (EM) of the drill winches and drill pumps R_MP и R_DW; of electric drives chokes at the input of rectifiers MP and DW L MP and L DW; electric motors AM TD, DC DW, DC MP top drive systems, drawwork and drill pumps.

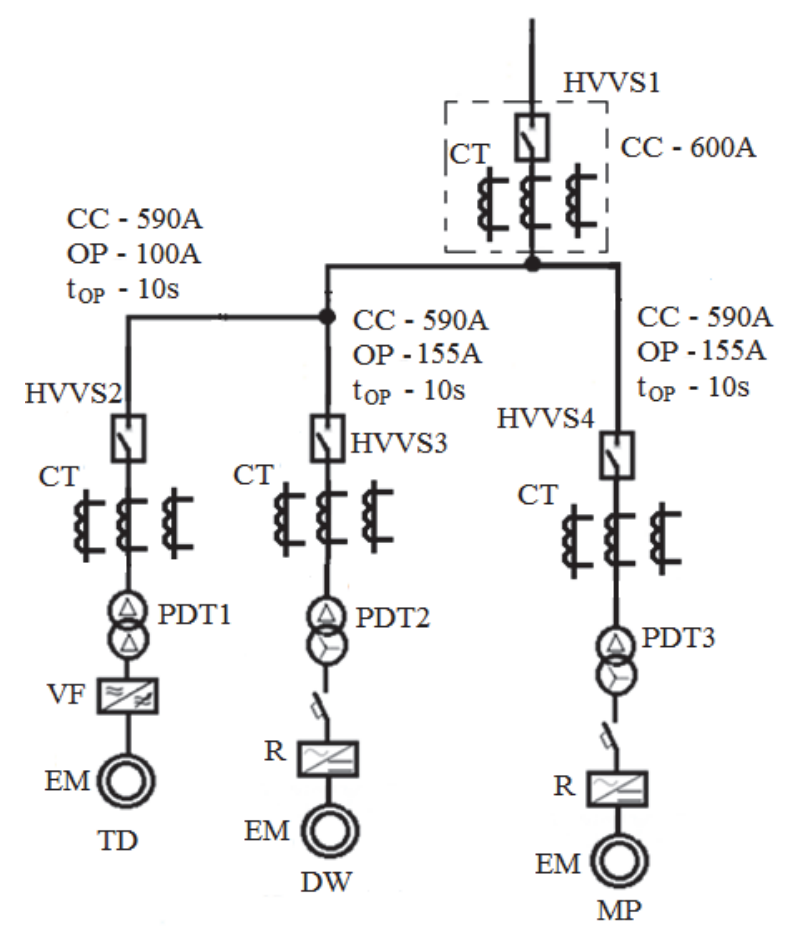

Fig. 1. The drill rig's power supply single-line diagram HVVS1...HVVS4 - high-voltage vacuum switches; PDT1...PDT3 - power dry transformers; CT - current transformers; VF - frequency converter; EM - electric motor; $\mathrm{R}$ - rectifier; $\mathrm{CC}$ - current cutoff; $\mathrm{OP}$ - overcurrent protection; TD - top drive; DW - drawwork; MP - mud pump.

The active resistances and inductances of the windings of the transformers, as well as the magnetizing circuits are given in relative units.

In the parameters of the electric motors, the values of the active resistances and inductances obtained in the identification process [6] of electric drives on drill rig (the data from the management systems of frequency converters and DC/DC converter) are entered. Recommendations were considered, a stationary reference frame [9] was used for electric motors for stator voltages that are unbalanced or intermittent.

The inverter uses sinusoidal modulation [10], a signal of the specified type is a sinusoid with a frequency of 50 $\mathrm{Hz}$, the carrier frequency is a triangular signal with a frequency of $1650 \mathrm{~Hz}$. This corresponds to the frequency modulation factor $\mathrm{mf}=33(50 \mathrm{~Hz} \cdot 33=1650)$ [11]. Power-up sensor "Chirp Signal" is an original development and generates a three-phase signal from the initial to the final frequency. The parameters which are set under the law $\mathrm{U} / \mathrm{f}=$ the window mode. The formation of the increase and decrease of the signal is provided according to the specified law. This depends on the actual frequency value and the reference at the input from the "Reference" block. System of pulse-phase control of DC / DC converters of a control motors with feedback on the speed and current. Data on electric 
motor loading from the mat-file using blocks, due to the formation of load blocks that are input to the motor Tm.

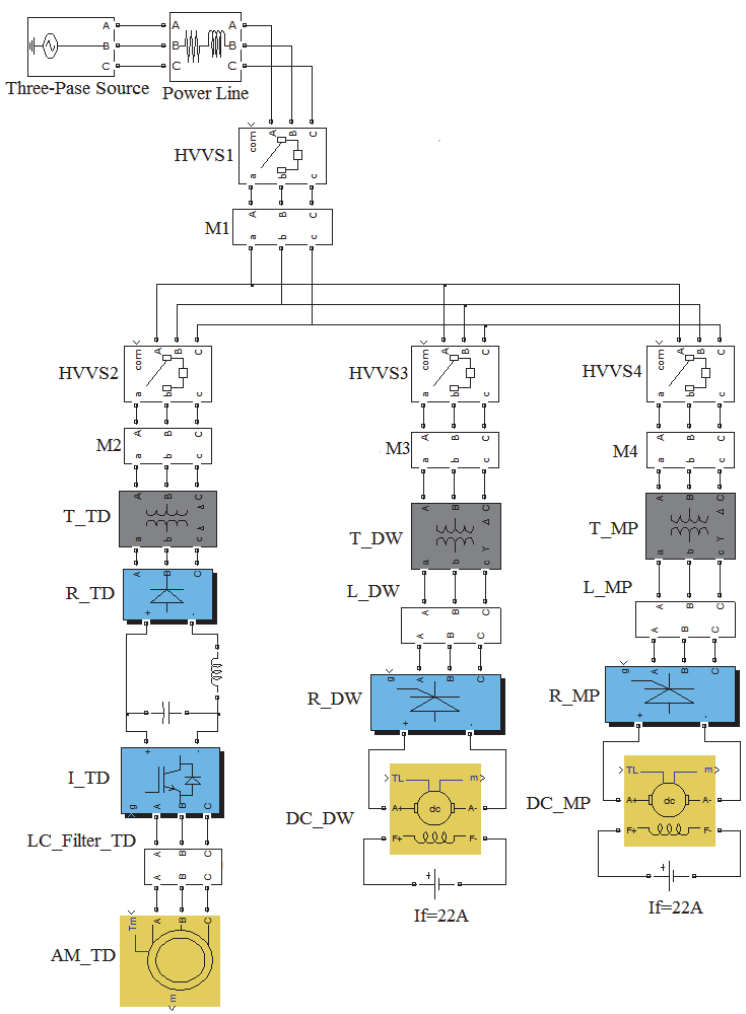

Fig. 2. Computer model of the electrotechnical complex of drill rig.

\section{The main results}

Figure 3 shows the relay protection model. We use the From block for control of currents, it takes data from the meter M. The Matlab system calculates the amplitude values of currents and voltages. Therefore, an RMS block is used to derive an effective current value that calculates the RMS value. To ensure the shutter response time MT3 we used block Discrete On/Off Delay.

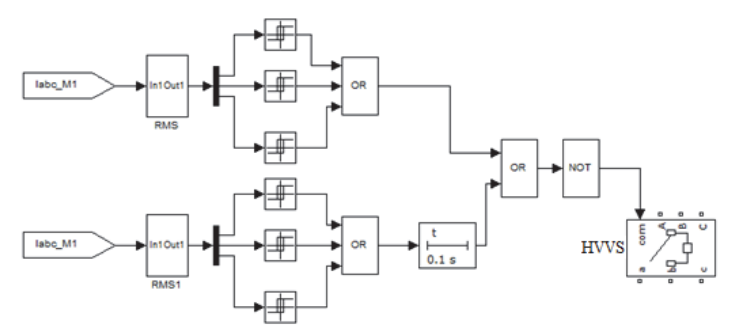

Fig. 3. Relay protection model.

Simulation of short circuits behind the transformer T MP that feed the electric drive Mud Pump is a threephase shorting "Three-Phase Fault" (Fig. 4). At the time $6 \mathrm{~s}$, an interfacial short circuit is produced. The simulation results are shown in Figure 5.

The protection relay tripping currents (TO in Figure 1) were not selected correctly and do not provide a trip for the circuit breaker in case of a short circuit, this was revealed by simulation. Therefore, the currents were reduced to $200 \mathrm{~A}$, which ensured the disconnection of the circuit breaker in the short-circuit behind the transformers. The results of the three-phase short-circuit simulation showed the necessity to correct the relay protection operation currents. As a consequence, this was done at the existing drill rigs.

The model of an electrotechnical complex of the drilling rig allows the modeling and investigation of the electrotechnical parameters at development drilling.

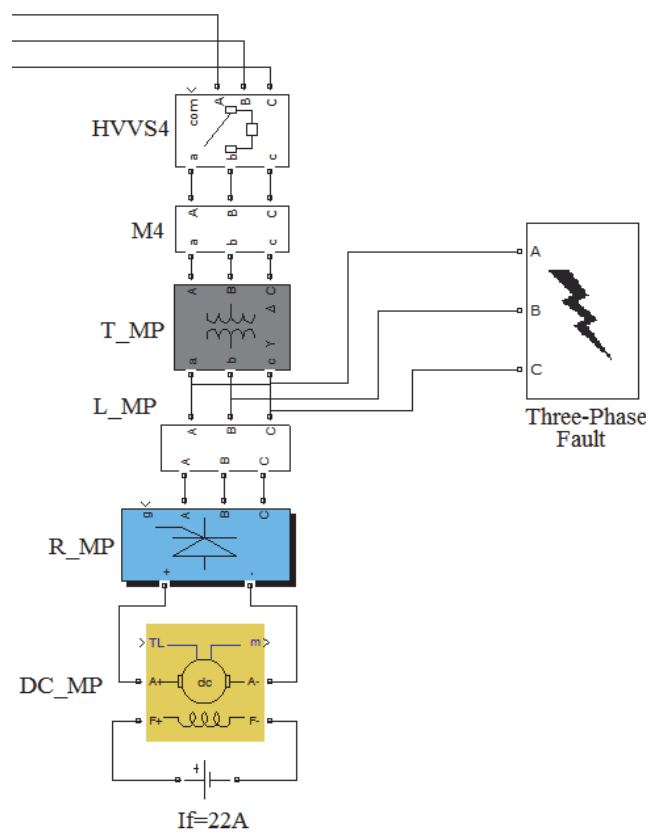

Fig. 4. Model simulating a short circuit.

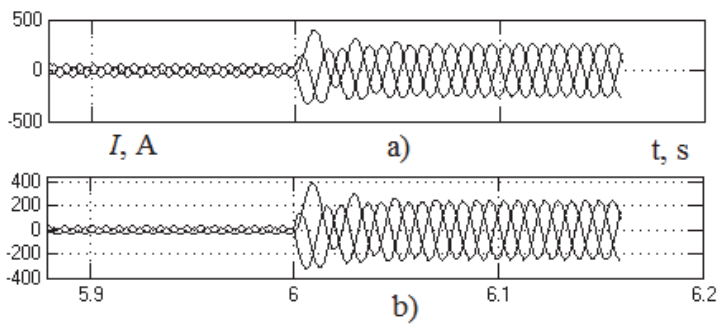

Fig. 5. The results of a simulation of short circuit behind the transformer T_MP: a) the currents in the power center for a breaker BB1- behind the switch HVVS1; b) the currents behind the breaker HVVS4.

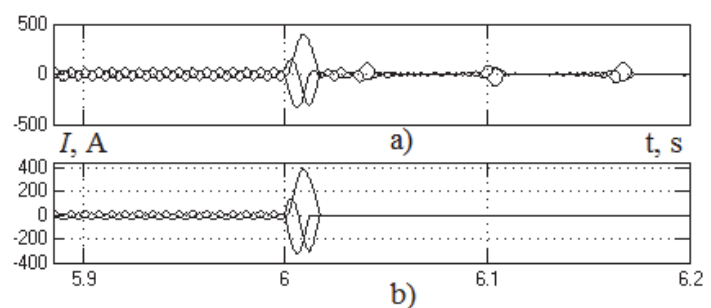

Fig. 6. Simulation results of short circuit behind the transformer T_MP with an adjusted operating current, relay protection of the switch HVVS4: a) the currents in the power center for a breaker HVVS1; b) the currents for circuit-breaker HVVS4.

Figures 7-8 show the results of the simulation of the electrical complex of the drill rig during the operation of 
well No 32409. Interval of depth of drilling of one boring candle from 603 to $628 \mathrm{~m}$.

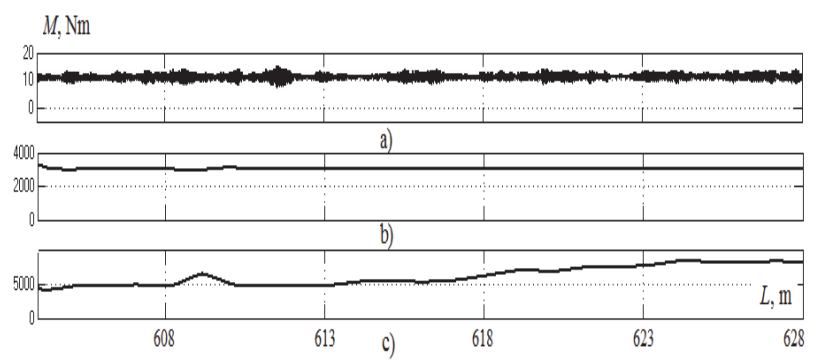

Fig. 7. Results of modeling the air gap torque of the electric motor.

a) the air gap torque of the electric motor of the top drive system; b) the air gap torque of the electric motor of the draw-work; c) the air gap torque of the electric motor of the mud pump

Data on electric motor loading from the mat-file using blocks, due to the formation of load blocks that are input to the motor Tm. Then data are unloaded for a certain interval from the control system of parameters of drilling. The load on the electric motor of the draw-work is kept constant, this provides a predetermined load on the bore bit.

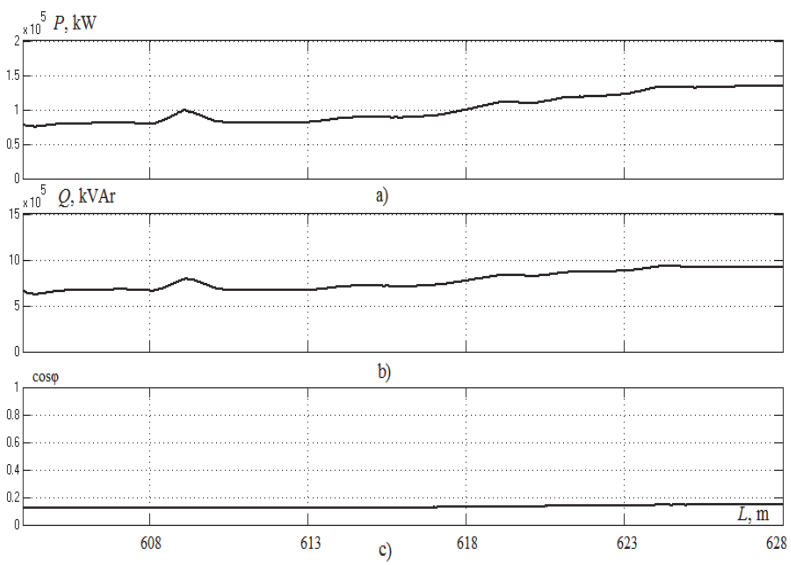

Fig. 8. Results of simulation of active (a) power and reactive (b) power and power factor (c) in the center of the power of the drill rig.

Figure 8 shows that in shallow drilling the electric network power factor is low.

When the well deepens the load of the drilling pump, the draw-work, the system of the top drive and the rotor increases, that changes all the parameters of the electrotechnical complex, including the power factor and the quality of electrical energy $[12,13]$. This is confirmed by the results of the simulation (Figures 7, 8): they show that when drilling a well N32409 at an interval of 603-628 m with an increase in the load of the electric motors of the upper drive system, the mud pump and the draw-work, the power factor is increases.

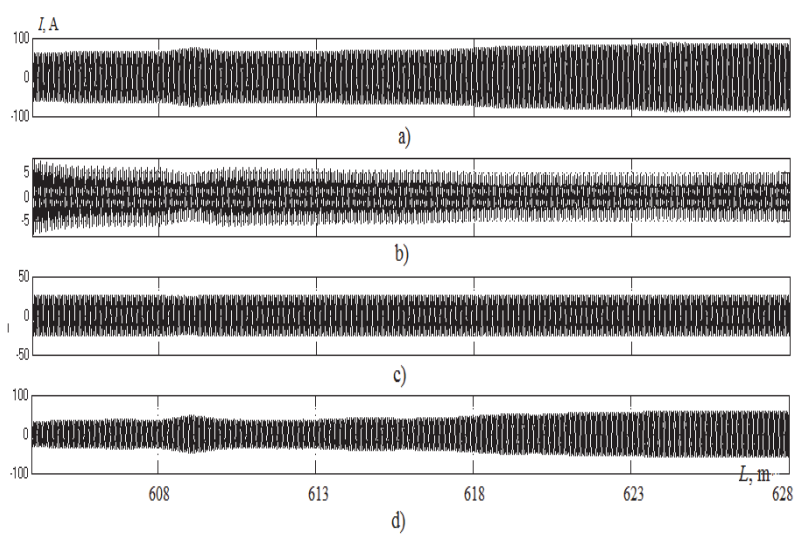

Fig. 9. Results of current simulation: a) the current in the power center; b) the current of the upper drive system; c) the current of the draw-work; d) the current drilling pump.

\section{Conclusions}

The developed model of the electrotechnical complex of the drill rig allows intestigation of the processes in the drill rig system in the event of emergency conditions, and selelcting the relay protection operation currents. It also allows researching processes using actual technological parameters in electric drives during the drilling of the well.

\section{References}

1. N. Y. Shevyreva, Quality Improvement of the Electric Power at Power Supply of Drill Rigs with Variable Frequency Drives (Ph.D. thesis in Engineering Science, 2016)

2. B. I. Abramov, O. I. Kozhakov, V. A. Shilenkov, V. K. Vasilyev, D. A. Ram, V. E. Kirillov, Proceedings of the VIII International (XIX All-Russian) Conference on The Automatic Electric Drive, 2 (2014)

3. B. Lotfy, K. Salakhkhoor, Oil and Gas, 3 (2013)

4. I.G. Kuliš, M. Skok, 23rd International Conference on Electricity Distribution Lyon (2015)

5. A. Smolarczyk, R. Kowalik, E. Bartosiewicz, 18th Power Systems Computation Conference (2014)

6. X. Zhan, G. Zeng, J. Liu, Q. Wang, S. Ou, International Journal of Advanced Computer Science and Applications, 6 (2015)

7. M.Y. Fedorova, Southern Ural state university Publishing the newsletter, 15 (2011)

8. Y.V. Shevyriv, D.A. Morgayov Bulletin of the Yuno-Ural State University. Series: Power. South Ural State University (National Research University), 15 (2015)

9. M.I. Grigoryev, S.V. Bukreev, Professional education and society. College of Modern Technologies. Hero of the Soviet Union Panova, 2 (2014). 
10. I.Y. Bykov, S.F. Zaikin, B.A. Perminov, V.B. Perminov, S.V. Poletaev, Z.Kh. Yagubov, Scientific and methodical electronic journal. Interregional Center for Innovative Technologies in Education, 20 (2017)

11. S.V. Bukreev, Advances in modern science, 10 (2016)

12. I.V. Chernykh, Simulation of Electrotechnical Devices in MATLAB, Simulink and SimPowerSystems. (DMK Press, 2008)

13. P.C. Krause, O. Wasynczuk, S.D. Sudhoff, IEEE Press (2002)

14. N. Mohan, T.M. Undeland, W.P. Robbins, Power Electronics: Converters, Applications, and Design, John Wiley \& Sons, Inc., New York 8.4.1. (1995)

15. Power System Blockset User's Guide. The Mathworks Inc (2000)

16. V.A. Shabanov, O.V. Nikulin, Rogtec Russian Oil and Gas developments, 44 (2016)

17. O.V. Nikulin, A.A. Zhilenkov, S.G. Chernyi, Automation in the automation in industry, 3 (2017) 